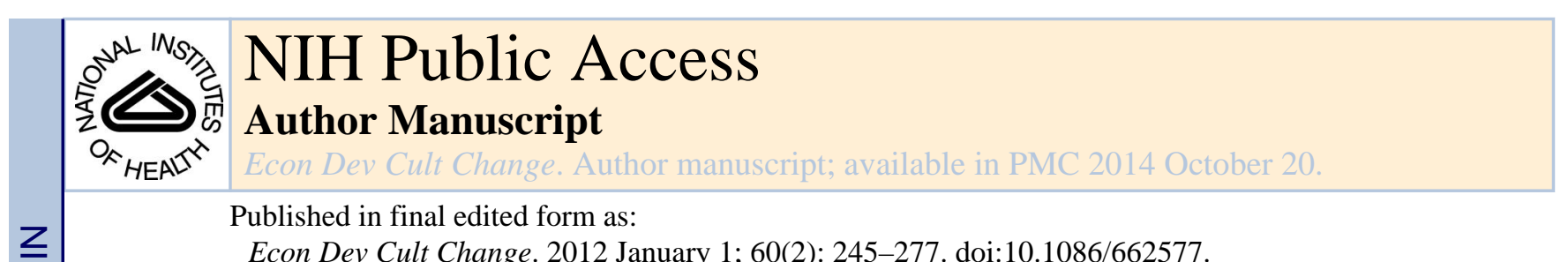

Econ Dev Cult Change. 2012 January 1; 60(2): 245-277. doi:10.1086/662577.

\title{
The Long-Run Impacts of Adult Deaths on Older Household Members in Tanzania
}

\author{
ACHYUTA R. ADHVARYU and \\ Yale University \\ KATHLEEN BEEGLE \\ World Bank
}

\section{Introduction}

The HIV/AIDS epidemic in sub-Saharan Africa has resulted in higher mortality rates among prime-age adults and sharp declines in life expectancy. The resulting "demographic hourglass" due to missing working-age adults has implications for a range of socioeconomic outcomes. These missing working-age adults were income earners who supported dependent children and, in some cases, their older parents. A World Bank (1997) report presents a detailed discussion of the direct and indirect ways in which an HIV/AIDS death may affect households and the means by which households might cope with these impacts.

Empirical research in this area in the African context focuses largely on the impact of HIV/ AIDS-related deaths on the outcomes of orphaned or fostered children specifically or households generally (see studies reviewed in Beegle and De Weerdt [2008] and Naidu and Harris [2005]). There are far fewer studies on the impact of prime-age deaths on older populations. Qualitative studies suggest that the impact could be large for older persons (Knodel and Landingham 2002; Knodel, Watkins, and Van Landingham 2003). There are important aspects of direct and indirect effects of prime-age mortality specific to older adults (see discussion in du Guerny [2002] and Messkoub [2008]). Surviving parents often bear the direct costs for ill adult children, including funeral and medical expenditures; indirect costs borne by the elderly include those associated with providing care to ill adult children, fostering-in of grandchildren, and the loss of remittances and income. ${ }^{1}$ In addition to these socioeconomic outcomes, there are potential psycho-social costs associated with losing a child or other household members.

There may be important gender dimensions to these impacts on older adults as well with respect to the gender of the older adult and the gender of the deceased. Gender inequalities in education, income, and property ownership may be important for understanding the impact of HIV/AIDS. ${ }^{2}$ Women are more likely to be caregivers, both of sick adults and of

\footnotetext{
(C) 2012 by The University of Chicago. All rights reserved.

${ }^{1}$ The burden of caring for orphaned children is perhaps the most often cited concern with respect to the elderly and HIV/AIDS epidemic (and rising prime-age mortality rates). Interestingly, even in countries in Africa with low HIV prevalence and/or where orphan rates are not increasing, grandparents are increasingly becoming caregivers of children (rather than either a surviving parent or other relatives such as aunts or uncles; Beegle et al. 2009). This fact suggests important changes in living arrangements that are not explained by HIV/AIDS and that have implications for the well-being of the elderly.
} 
children fostered in the household. For example, a survey in South Africa showed that twothirds of caregivers were women and that a third of them were older than age 60 (Steinberg et al. 2002, cited in UNICEF 2004). Gender inequalities in access to off-farm income opportunities make remittance income and (dis)inheritance of assets more salient issues for women. Women in many African settings have less secure rights to land and assets, raising concerns about women being dispossessed of assets when widowed or when another (male) household member dies.

Evidence of such events often comes from case studies; evidence from sample survey efforts is lacking. One exception from Malawi is somewhat contrary to expectations. The national household survey in 2004-5 found that the average value of land and assets lost after a male death in the household was actually lower in the patrilineal North region, where women traditionally have fewer rights to assets, compared with the South and Central regions (Republic of Malawi and the World Bank 2007). This finding likely reflects rapid changes in national laws and local customs. For example, for the 51 villages in the Tanzania data used in this study, in 1991,39\% of village informants reported that the norm in the community allowed a woman to inherit land when her husband dies. In 2004, 86\% report that this is the norm. Although male deaths, including those of husbands and sons, may be more salient for women than men with respect to assets and income, deaths of prime-age women may matter for nonmonetary reasons. Adult daughters are more likely to be care-givers to their elderly parents, making older adults potentially vulnerable to a lack of care if they lose daughters. Combined, the speculation is that, faced with the death of a working adult family member, older adults in Africa, especially women, will be left with fewer income sources and assets, need to work more, and face greater poverty and poorer health.

Despite well-developed theories about the pathway and speculation about the magnitude of impacts (see, e.g., Ferreira 2004), there exists little systematic empirical evidence about the effects of adult death on older household members (Knodel et al. 2003). Knodel and his coauthors have several studies on the elderly in Cambodia and Thailand; there is much less evidence for sub-Saharan Africa. The most rigorous sample survey-based evidence arguably comes from South Africa (see, e.g., studies in Cohen and Menken [2006]). ${ }^{3}$ Yet the combination of the old-age pension scheme, which provides cash transfers to older adults, and the very severe HIV epidemic suggests that the impacts observed in South Africa may be quite different than the impacts in other African countries (Hosegood and Timaeus 2006).

Moreover, most of these studies focus on demographic impacts (living arrangements, population age/gender structure) rather than more direct measures of economic impacts. Another problem is that many studies in this literature tend to have small, often specially selected samples, and the studies are case-based; see, for example, Agyarko (2002) and Ogunmefun (2007). These studies lack discussion of the problems of endogeneity in both

\footnotetext{
${ }^{2}$ Gender inequalities may also be a driver of the transmission of HIV. The related literature is not discussed here. Likewise, children may be differentially affected by the loss of their parent along gender lines. Several studies find that maternal mortality affects schooling more than paternal mortality (Beegle and De Weerdt 2008).

${ }^{3}$ Although not focusing specifically on the elderly, in the journal AIDS (November 2007, vol. 21, suppl. 7, on "Poverty, HIV and AIDS: Vulnerability and Impact in Southern Africa"), seven of the 10 papers are on South Africa, one is on Zimbabwe, and two are cross-country studies.
} 
living arrangements and mortality events (i.e., deaths do not randomly occur in this context). The existing evidence is usually not longitudinal in nature, thus prohibiting an understanding of the total impact of HIV/AIDS over time (Naidu and Harris 2005). It is often presumed that studies may understate impacts if households use coping strategies, such as assistance from neighbors or selling off assets, that may mitigate direct impacts on well-being, at least in the short run (World Bank 1997). Long-run impacts may differ from evidence drawn from short-run panel data (see, e.g., Carter et al. [2007], who explore three rounds of a 12-year household panel in South Africa). Furthermore, there may be specific gender dimensions (with respect to the gender of the deceased and the survivors) that warrant further study.

The objective of this study is to provide empirical evidence of the impacts of adult deaths on older adults using long-run panel data from Kagera, a region in northwest Tanzania. Using a longitudinal data set covering 13 years, we analyze a sample of individuals who were age 50 or older in 2004. The time span of the data allows us to assess long-run impacts of adult death, with particular attention paid to gender dimensions of the surviving older adult and the deceased. We focus on several outcomes. We explore how working hours are affected by adult deaths; the underlying premise is that prime-age deaths weaken support to older adults, both financial (remittances in cash and in-kind) and through labor sharing in farming and household activities. This, in turn, may result in older adults having to work more to sustain their household. We look for evidence that the impact on work varies by length of time from the death shock and by the asset position of the household prior to the shock. We extend our outcomes to also include more direct measures of well-being, including health and consumption.

Earlier work by Ainsworth and Dayton (2003) and Dayton and Ainsworth (2004) examines the short-run impacts of adult death on the elderly using the first 4 years of the same panel data set we use. The authors find that the body mass index (BMI) of older individuals drops just before an adult death but then recovers to the previous level afterward. We extend the work of these studies by focusing on long-term impacts (up to 13 years after an adult death) and by analyzing changes in the labor supply of the elderly in addition to health outcomes. We also construct indicators for prime-age adult mortality that reflect the complexities of household composition. These include measures of coresidency over time and deaths of biological children who may never have resided with the parent at baseline.

We find that prime-age deaths occurring while the deceased adult was living with the elderly respondent are associated with increases in working hours of older women. For older men, labor increases are associated when the deceased was not a household member at the time of death, but with less precision. The impacts are more pronounced when the deceased was a younger prime-age (15-29 years) coresident. For noncoresidents, the labor increase is associated with older prime-age (30-49 years) coresidents. The impacts are mainly for deaths in the distant past, suggesting that shorter-run studies may not capture the full extent of the consequences of adult mortality for survivors. Older adults with greater assets are able to buffer the labor supply response for deaths of coresident members. Most health indicators were not worse for older adults who experienced a death shock in the household (similar to the findings of Ainsworth and Dayton [2003] and Dayton and Ainsworth [2004]), although more distant deaths were associated with an increased probability of acute illness of 
surviving adults. We find no impact on hours worked or health of deaths of biological children who were not household members of the older adults at baseline.

Some of these results are consistent with theories put forth on the impact of prime-age mortality: that women will bear more of the burden (although only slightly more in our study), that longer-run impacts may be greater, and that assets can help households buffer impacts. On the other hand, some results are at odds with these theories. Impact of hours is minimal, we see few health impacts, and biological adult children are not associated with worse outcomes for older adults.

The rest of this article is organized as follows. Section II describes the data and defines the key dependent and independent variables. Section III lays out our empirical strategy and discusses the various types of bias on the measurement of the impact of adult death. Section IV presents our results, and Section V concludes.

\section{Data}

\section{A. Geographical Context and Data Summary}

This study uses survey data from the Kagera region of Tanzania, an area west of Lake Victoria bordering on Rwanda, Burundi, and Uganda. Kagera is mostly rural and is primarily engaged in producing bananas and coffee in the north and rain-fed annual crops (maize, sorghum, and cotton) in the south. The region is an area of early and high HIV prevalence, which has led to a significant increase in prime-age mortality rates. Kwesigabo et al. (2005) report on three population samples in 1987 in districts of contrasting exposure in Kagera, and they find an overall age-adjusted HIV prevalence of $24.2 \%$ in the urban Bukoba district; of $10.0 \%$ in the Muleba district, a medium-prevalence area; and of $4.5 \%$ in Karagwe district, a low-prevalence area.

Subsequently, prevalence rates in the region have dropped rapidly, which has been attributed both to mortality of those infected and lower incidence (as measured by repeat testing of the original population-based sample). In urban Bukoba, prevalence decreased to 18.2\% in 1993 and $13.3 \%$ in 1996. In the other areas studied, prevalence also declined considerably, to 4.3\% and 2.6\% in Muleba and Karagwe, respectively. Kwesigabo et al. (2005) note that the decline in these areas of different initial HIV exposure suggests that the epidemic may have been arrested early without necessarily peaking to "saturation levels" (in which all people most at risk are infected). Nevertheless, and of relevance to our study, a rapid decline in prevalence, even without a change in the incidence of HIV, is only possible through a high mortality rate in this period.

The Kagera Health and Development Survey (KHDS) was conducted by the World Bank and Muhimbili University College of Health Sciences (MUCHS) and consists of 915 households interviewed up to four times, from fall 1991 to January 1994, at 6-7 month intervals (World Bank 2004). The sample was stratified based on illness and mortality prior to the first round (see World Bank [2004] for details), and this stratification is controlled for in all regressions. The follow-up, the KHDS 2004, was conducted in the first half of 2004 (Beegle, De Weerdt, and Dercon 2006). 


\section{B. Older Adults}

We analyze outcomes for the surviving 2004 sample of older individuals who were in the original KHDS baseline interview in $1991 .{ }^{4}$ In keeping with the literature on older persons in developing countries, we define older adults as above the age of 50 in 2004; thus, these individuals were as young as 37 years in 1991. The data contain 1,060 individuals in the category of older adults, as defined here. Of these, 613 were reinterviewed in 2004.

We make note of two things with respect to the sample. First, the youngest of our sample of older individuals (those who were just above 50 years old in 2004) were younger than 50 for the majority of the time span we study. Approximately $25 \%$ of the sample was younger than 50 at baseline. That is, our sample of "older adults" is actually not so old at baseline.

However, given the long span of the data set, we face a trade-off between two definitions for the sample of older adults: (i) not-so-elderly at baseline and aging into older adult status by 2004 or (ii) elderly at baseline and very old (or already deceased) by 2004. We choose to focus on the former definition. We discuss the merits of this choice below after introducing our adult death variables.

Second, the main cause of attrition in the sample of elderly individuals over the 13-year span of the panel is death. Of the 1,060 individuals at baseline who would have been over 50 in 2004, 403 (38\%) died in the 13-year span of the panel and 44 (4\%) were not located for resurvey. We return to this issue below when we explore the correlates of attrition. Of the 613 respondents who were reinterviewed, $87 \%$ lived in the same community in which they were interviewed 13 years earlier. This age group is much less geographically mobile compared with younger age groups in the KHDS, of which 59\% of those reinterviewed lived in the same community. Few of the older adults lived alone, although the rate increased from about $3 \%$ to $7 \%$ by 2004 . The average household size of the elderly sample is larger than younger age groups in the KHDS, and it declines from 6.7 to five persons over the panel. Most of the 2004 elderly individuals were living with their sons, daughters, or grandchildren in 2004 (see table 1 for a summary of living arrangements for the elderly).

\section{Adult Death}

Our main independent variable is a binary variable indicating whether there was a prime-age death in the older individual's household between baseline (1991) and 2004. We define "prime age" as ages $15-50$, inclusive..$^{5}$ About $96 \%$ of our sample resided with at least one other person at baseline who may have died at age 15-50 by the follow-up round in 2004 (i.e., someone between the ages of 2 to 50 years). Since the data set spans 13 years, the term "household" cannot be well defined. Although the elderly are less geographically mobile (i.e., they are more likely to live in the same village than younger respondents), the composition of their household changes over the course of the panel. Of the 613 elderly individuals in 2004, only 84 had a household of the same size and only 14 lived in a

\footnotetext{
${ }^{4}$ Because we are focusing on long-run impacts, we do not use data from the second to the fourth rounds (collected at roughly 6 month intervals from mid-1992 to late 1993) of the KHDS. Earlier studies, including Ainsworth and Dayton (2003) and Beegle (2005), do explore labor and health impacts using the four rounds from 1991 to late 1993.

5 We do not specifically try to ascertain the cause of death. Instead, we focus on mortality among prime-age adults; other studies have found that a majority of these deaths are caused by HIV/ AIDS (Centers for Disease Control and Prevention 2000).
} 
household with exactly the same group of panel respondents as at baseline. It is thus clear that living arrangements changed for the elderly over the course of the panel (as they did, in fact, for respondents of all ages). These changes reflect life-cycle events such as children moving away after marriage and responses to shocks (e.g., the fostering in of an orphaned child).

Our variables for adult death must thus take into account the changing nature of the household over time. To this end, we use three indicator variables reflecting different types of adult deaths that can potentially have an impact on the socioeconomic situation of the elderly. The first equals one if all the following conditions are satisfied: (i) the adult who died was of prime age (15-50) at the time of death, (ii) the adult was part of the elderly individual's baseline household, and (iii) the elderly individual and the prime-age adult were living together at the time of death. We refer to these deaths in our results as "coresident PHHM who died ages 15-50," where PHHM stands for previous household member. The majority of these deaths are close relatives of the respondent: child (62\%), spouse (9\%), grandchild (8\%), sibling (3\%), and other relation (18\%), which includes son and daughter in-law, niece or nephew, and other in-law.

The second binary variable corresponds to the death of a previous household member (i.e., an adult who was living with the elderly individual at baseline in 1991) who died while living away from the elderly person. We include this group in consideration of the fact that elderly individuals in this region may receive cash or in-kind support from previous household members who later reside in another household. The variable equals one if all the following conditions are satisfied: (i) the adult who died was of prime age (15-50) at the time of death, (ii) the adult was part of the elderly individual's baseline household, and (iii) the elderly individual and the prime-age adult were not living together at the time of death. We refer to this variable in our results as "noncoresident PHHM who died ages 15-50."

The third binary variable corresponds to the death of noncoresident biological children of the elderly at baseline, who again may be important through their monetary support to other household members. We construct a binary variable that equals one if (i) the elderly individual had a noncoresident child living at baseline who would have been 15-50 in 2004 and (ii) at least one such child died between 1991 and 2004. Note that this definition is slightly different from the previous ones because here children living elsewhere who died before the age of 15 may still be included if they would have been 15 by 2004 .

Due to data restrictions, we omit an important category of prime-age adults in these definitions. An elderly individual may have been living with prime-age adults who died who were not part of the baseline sample. Since the retrospective mortality questionnaire in the 2004 survey does not ask about these deaths, they will be omitted from the prime-age death variable defined above. That is, we are missing some mortality events among both those who are identified as having experienced none of the three death shocks defined above and those with such a death. To this end, our results need to be interpreted narrowly with our specific definitions in mind. With respect to a more general study on the impact of mortality, our results are likely to be underestimates of this impact. 
The survey data also record the year in which prime-age individuals died for the first two adult death variables described above. In some analyses, we construct and use binary variables corresponding to the death of a prime-age household member during three periods of the panel: 1991-95, 1996-99, and 2000-2004.

A crucial question that arises, given the long time span of our panel data, is the age the the surviving older adults (who were as young as 37 at baseline) relative to that of their deceased prime-age household members (who were between 15 and 50 years old at the time of their death). Indeed, it is conceivable, given our definitions, that an older adult in our sample may have been younger than the prime-age adult at the time of the latter's death. If this were true in enough cases, the question under investigation-uncovering the effects of prime-age mortality on older adults—would be changed.

To investigate the extent to which this is true, we plot histograms for the age distribution of our sample of older adults (fig. 1) and the age distribution (age at time of death) of their deceased household members (fig. 2). Figure 1 shows that a significant proportion of older adults in our sample are between 50 and 63 years old (43\%), and would thus have been younger than 50 (i.e., prime age) at some point between 1991 and 2004. However, figure 2 shows that only 30 of $264(11 \%)$ deaths of prime-age household members occurred between ages 40 and 50 .

This overlap in age distributions exists because of the sample restriction we make. If we had chosen the latter of the two choices alluded to earlier (restricting our sample to all individuals who were already 50 or above in 1991), we would no longer face the problem of overlap in the age distributions. However, the trade-off would have been a large reduction in sample size: only 352 of the 613 older adults (57\%) in our sample were older than 63 in 2004 , which means that our sample would have shrunk by $43 \%$. We have thus chosen, keeping in mind the costs of our choice, to augment our sample by including individuals who were older adults (older than 50) by 2004 but who may have been in prime age during some part of the panel.

\section{Ouxtcome Variables}

Our analysis examines several outcome variables related to labor, health, and food consumption. The labor supply variables include farm hours (including hours on own farm, community farm, processing crops, herding, and processing livestock); wage employment hours, self-employment hours in nonfarm work, hours spent gathering firewood and fetching water, and total hours, which is the sum of hours spent in all categories of work just mentioned. These variables correspond to hours spent in each activity in the 7 days prior to the day the household was surveyed. Labor intensity in rural Africa settings is quite difficult to measure due to the predominance of farming and the seasonality in labor hours. The survey did not try to construct an annual estimate of labor hours. We do not include hours spent in housekeeping and childcare, partly because these data would be prone to large measurement error.

The average number of hours worked per week, reported in table 2, is below 30 hours, and this may appear low. These numbers are actually quite similar to national survey estimates 
from neighboring countries. For example, they are similar to the hours for individuals in rural households in the Malawi 2004-5 Integrated Household Survey and the Kenya Integrated Household Budget Survey 2006-7 (results not reported). This can be explained in at least two ways. First, in rural areas the main economic activity is farming, which leads to large seasonal variation in labor supply (Cleave 1974) such that the timing of surveys matters. In both the Kenya and Malawi surveys noted above, field work is spread over 12 months. In the case of the KHDS, field work was spread over about 6 months in the first half of the year, which covered some periods of peak labor demand for the long rainy season but was not conducted solely in that period. High seasonal variation is likely to be less of an issue in Kagera, although there is relatively more continuous cultivation of bananas and coffee than in regions with seasonal farming (those with more prominent bimodal or unimodal rainy seasons). Second, hours will be low in areas with low land holdings per household member such as Kagera (which may be evidence of surplus labor).

We use the following health outcomes: body mass index (BMI); an indicator for selfreporting of an illness in the 4 weeks prior to the survey; an indicator for chronic illness, which is any current illness that has lasted more than 6 months; days of restricted activity due to illness or injury in the week prior to the survey; and days of no activity due to illness or injury in the week prior to the survey. We also examine food consumption per adult equivalent in the household. ${ }^{6}$

\section{E. Controls}

We control for the following set of baseline characteristics at the individual and household levels: gender, highest grade completed, a quadratic in age, season of interview, assets, household size, the number of children living outside the household, and an indicator for sample enumeration classification (which equals one if the elderly individual's initial household had experienced an illness shock prior to 1991). ${ }^{7}$ We also control for the histories of crop and illness shocks in each year over the time span of the panel.

\section{F. Summary Statistics}

Table 2 reports means for dependent and independent variables for four groups: the pooled sample of elderly individuals at baseline, the subsample reinter-viewed, and, among those reinterviewed, elderly individuals who did and did not experience a prime-age death in the household.

Comparing the first two columns in table 2, we find some statistically significant differences between the baseline characteristics of older adults rein-terviewed in 2004 and the entire sample $(1,060)$ including those who died. Those reinterviewed were more likely to be female, younger, to have worked more, and to be healthier in 1991. We address this selective attrition bias using the reweighting procedure described below.

\footnotetext{
${ }^{6}$ The scale for calculating adult equivalent household size is the same scale used by the Tanzania National Bureau of Statistics for the analysis of poverty using the Household Budget Survey data. It is an adjustment based on the age and gender of household members, where non-adult males have weights below 1. It does not account for economies of scale in household consumption.

${ }^{7}$ In results not reported in this article, we reproduce all the tables using a specification that controls for initial household composition (in addition to household size), i.e., it controls for the number of individuals in the household stratified by gender and age groups. The main results are unchanged.
} 
Among the 613 older adults we study, we observe some statistically significant differences in baseline characteristics between those who did and those who did not experience a death before 2004 (bottom half of table 1, cols. 3 and 4). Those who would experience a death were more likely to be women, to be doing less farm work and chores in 1991, and to have more wage employment. The differences we observe at baseline indicate that deaths are not necessarily random events, an issue discussed in more detail below. In 2004, the only significant difference between those who experienced a death shock and those who did not was in BMI. Older adults who had a death shock had a higher BMI than their counterparts with no death shock.

\section{Empirical Strategy}

We begin with a basic empirical model of the relationship between elderly outcomes $(y)$ and prime-age death in the household $(d)$. We index elderly individuals by $e$ and (baseline) households by $j$. The regression is on a cross section of elderly individuals in 2004 . We make use of the panel dimension by using the change in the outcome $y$ from 1991 to 2004 as the left-hand-side variable: $\Delta y=y_{2004}-y_{1991}$. Prime-age death could have occurred at any point during the period spanned by the panel, from 1991 to 2004. The model is as follows:

$$
\Delta y_{e j}=\alpha+\beta_{1} d_{j}+\beta_{2} X_{e j}+\varepsilon_{e j} \quad \text { (1) }
$$

Here $X$ is the vector of control variables from the baseline round described in the previous section. This model is different from a first-difference speci-fication as the independent variables are not differenced over time while the outcome variable is. We adopt the specification presented above, which is akin to the empirical model used in Beegle, De Weerdt, and Dercon (2007), rather than a first-difference specification because changes in the explanatory variables and changes in the outcome $y$ are likely to be jointly determined; thus, including $\Delta X$ instead of $X$ as explanatory variables could bias estimates of the effect of prime-age mortality.

\section{A. Endogeneity Issues}

There are two possible sources of omitted variable bias after controlling for the observed baseline characteristics as described above: endogeneity with respect to deaths and endogeneity with respect to living arrangements. Regarding the first issue, the presumption is that a significant portion of deaths are caused by AIDS, a disease typically contracted through distinct patterns of behavior in this setting (see, e.g., Philipson and Posner 1995). Certain individuals (and families) may be more likely to suffer an AIDS death. For example, poverty is often cited as a key driver of transmission of HIV/AIDS (Fenton 2004), although the evidence of this link tends to show the opposite association (as noted by Shelton, Cassell, and Adetunji 2005; Wojcicki 2005; Gillespie, Kadiyala, and Greener 2007; and Glick (2007). In their study of eight sub-Saharan African countries, Mishra et al. (2007) find that wealthier adults are more likely to be infected with HIV, although this association is very weak after controlling for urban/rural residence and education. Other traits, such as risk aversion, may be inversely correlated with prime-age mortality. In turn, these household/ family characteristics associated with prime-age mortality may also be correlated with our 
outcomes of interest. Although we partially address this by including baseline (pre-death) covariates, we cannot entirely control for unobserved covariates that may bias the results.

One strategy to address the endogeneity caused by unobserved correlated behaviors, preferences, and discount factors within the household exploits the fact that most households branch out over the relatively long time span of the panel (see, e.g., Beegle et al. 2007). Two individuals in the same household at baseline (in 1991) could split into separate households at some point during the panel, and thus they experience a different history of household mortality over the course of the panel's 13-year time span. Thus, if we condition on this "dynastic" (otherwise referred to as "initial household") fixed effect, we would be eliminating the correlated behavior and preferences of individuals within these initial households. We would identify the effects of adult death using variation in the history of mortality within dynasties/families. However, our sample of older individuals, unlike the sample of all household members in Beegle et al. (2007), is small, and thus the dynastic fixed effects model would lack statistical power. Among the 613 older adults we follow from baseline to 2004, only 274 of them are coresiding with at least one other older adult at baseline. Restricting the sample to these individuals would likely lead to selection bias: those individuals whose initial household structure permitted or required them to live together may react very differently to mortality shocks. Thus, we do not attempt to compare outcomes across members within the same dynasty/family; instead, we partially address endogeneity by examining changes in outcomes of interest $(\Delta y)$, which removes individual (and household) time-invariant effects.

The second source of endogeneity is choice of residence. The event of a death among household members is a reflection of household composition, which can be endogenous. Two pieces of evidence support this idea in the KHDS data. First, there is a high degree of change in household composition over time. Second, within the first four rounds (1991-94) of the KHDS, about one-third of all adult deaths in the data are among people who move into the household within 6 months of dying. To the extent that individuals chose to live in households in response to illness or recent death, the event of death in their household is endogenous. In part, we rely on the length of the panel to address this concern. First, AIDS deaths (as well as other deaths caused by major illnesses in this region) are preceded by serious morbidities. In the KHDS baseline, on average, illness began 12 months before the event of a death. For the vast majority of the deaths in our sample, both the baseline and the 2004 data are more than 1 year from the onset of symptoms and the death. So the majority of these deaths had a preceding illness whose onset with respect to observed morbidities was after baseline. In that case, we do not expect that either the surviving older adult or the ill household member would have anticipated the future death with respect to 1991 living arrangements. Second, while there is evidence that adult children move back in with their parents when very ill and shortly before they pass, this type of death is largely eliminated from our sample or combined with deaths of other children regardless of coresiding with the parent at time of death (our third death indicator). 


\section{B. Attrition Bias}

As mentioned earlier, there is a great deal of attrition in the sample over the 13 years of the panel, as table 1 shows. This attrition is almost wholly due to death (i.e., deaths of elderly individuals). Of the 1,060 potential elderly individuals in the first round of the survey (those individuals who were surveyed who would have been older than 50 in 2004), 403 (38\%) had died by 2004 and only 44 (4\%) were not located. Most of the deaths, 85\%, were reported to be due to illness rather than injury or accident. Among the $61 \%$ of deaths, the specific causes range from blood pressure, malaria, cancer, AIDS, tuberculosis, and unknown cause (each at about 10\%). The median length of the illness that preceded death was 3 months, but the mean was much higher, about 17 months. The consequence of this attrition is that we estimate the impact of prime-age deaths on elderly outcomes using the remaining sample of older individuals who were still alive in the fifth round of the panel (2004). Attrition is, as expected, strongly correlated with age. Of the 1,060 baseline respondents in our sample, $24 \%$ of those younger than 50 in 1991 were deceased by 2004, compared with $46 \%$ of those older than 50 .

Using this selected sample may lead us to incorrectly identify the effect of a prime-age death on an elderly individual. For example, if the older adults who were still alive in 2004 were healthier or more able to do physical work than the individuals who died, then the labor supply response of these individuals to an adult death may have been very different than that of an older adult on average. In our case, in which attrition in the elderly sample is primarily because of the death of elderly individuals, we would expect attrition to be driven by both observable and unobservable determinants.

To correct for attrition bias due to selection on observables, we use a standard inverse probability weighting procedure (Wooldridge 2001). The procedure involves weighting regressions using probability weights estimated from an attrition probit model. In addition, attrition itself, since it is largely a function of survival, is in some sense a welfare outcome.

We model attrition in the canonical way as follows. The dependent variable, $\Delta y_{e j}$, is observed only if the individual is alive in the last round of the survey $\left(A_{e}=1\right)$. Then,

$$
\begin{gathered}
\Delta y_{e j}=\alpha+\beta_{1} d_{j}+\beta_{2} X_{e j}+\varepsilon_{e j} \quad \text { observed only if } A_{e}=1 \\
A_{e}^{*}=\delta_{0}+\delta_{1} Z_{e j}+v_{e j} \\
A_{e}=1 \quad \text { if } A_{e}^{*} \geq 0 \\
A_{e}=0 \text { if } A_{e}^{*}<0
\end{gathered}
$$

We estimate the attrition equation by regressing the binary variable $A_{e}$ on baseline determinants of attrition, including individual and household-level demographic and socioeconomic characteristics, as well as baseline health and labor variables $\left(Z_{e j}\right)$. We report the results in table 3 . We then use the estimated coefficients to predict the probability of 
survival to the last round of the survey, and we use this probability to construct attrition weights, which then weight the observations in our outcome regressions. Although this procedure can address the attrition associated with baseline characteristics, it does not resolve the issue that the death of a prime-age adult in the household may in itself contribute to attrition through the outcomes we examine (labor and health). If the death of a household member after baseline results in the elderly individual working longer hours and having poorer health, these effects, in turn, may result in higher mortality rates for the elderly. Under this scenario, our findings on labor and health outcomes are then underestimates of the actual impacts of deaths. We partially address this issue by including mortality events during the first waves (1991 to early 1994). We also estimate hazard models (both Cox and Weibull) of deaths of our baseline sample and the incidence of deaths of prime-age members during the panel (as a discrete time-varying covariate). We do not find that older adults experience greater mortality risks due to prime-age deaths (results not presented).

Table 3 shows that attrition is correlated with the age and gender of the older individual; older individuals and men are more likely to attrite from the sample. Widowed men were especially likely to die before 2004. The coefficients on the correlates of attrition are similar for women and men (cols. 2 and 3). Finally, we see from the table that living in a household that experienced the prime-age death of a previous household member does not affect the probability of attrition (col. 4). Although there are some baseline characteristics associated with attrition, the weighted results below are not different from the unweighted findings (results not presented).

\section{Results}

\section{A. Labor Outcomes and Adult Death}

We first examine the labor outcome impacts of deaths between 1991 and 2004 of previous prime-age household members or of an adult child living outside the household at baseline. ${ }^{8}$ In all regressions, we control for baseline demographic and household characteristics. Since farming is the main economic activity in the region and constitutes the greatest share of work time, we first focus on farm hours alone. The average change in weekly farm hours from 1991 to 2004 was small and negative, a decrease of about 1.3 hours; on average the elderly worked about 15 farm hours per week in 2004 (table 2). In table 4, column 1, we report estimates of the impact of the composite death indicator on the change in farm hours from 1991 to 2004. When we control for covariates, older adults who had a death shock experience an increase of about 1.8 hours in the change in farm labor over time relative to those with no such shock (which is large enough to fully offset the small decrease in hours we observe at the mean), although this coefficient is not significantly different from zero.

In table 4, column 2, we split the death variable into its three constituent categories: death of a coresident adult previous household member, death of a noncoresident adult household member, and death of an adult child living outside the household. Again, we find no

\footnotetext{
8 In tables 4-9, we split the death variables in various ways, but the low prevalence of death shocks limits the number of ways we can divide/interact the death covariates. For example, we cannot explore the deaths of previous household members by age group, gender of older adult, or relationship of the deceased to the older adult.
} 
significant impact of any of the categories of adult death on labor hours for older individuals. In column 3 of table 4 , we interact the three death variables with a dummy that equals one if the older individual is female. The results reveal an important gender dimension of the impact of adult mortality: the death of a coresident adult PHHM (previous household member) is associated with a lesser negative change in labor for female elderly individuals but not for males. For males, there is a less negative change in working hours with the death of noncoresident adult PHHM. The change in labor hours for those whose children living outside the household died is small and not statistically significant.

In table 5, we report results of regressions in which the two PHHM death categories have been further broken down by specified characteristics. Each column in table 5 is a separate regression. Now instead of three main death categories, we have five. The data set does not allow us to perform the same breakdown for the children living outside the household death variable as for PHHMs. Each column (regression) in the table corresponds to a specified characteristic along which we have broken down the PHHM death variables.

In column 1, we examine whether the impact of adult death on labor outcomes for the elderly varies by the age of the deceased adult. We split (coresident and noncoresident) PHHM deaths into deaths of young (15-29 years) and not young (30-50 years) adults. The results show that the impact of adult death varies both by residence status and by the age of the deceased adult. For coresident PHHM deaths, younger adult deaths are associated with smaller decreases (i.e., we have a positive coefficient estimate, but the mean change in the outcome is negative) in labor hours. The coefficient estimate (5.5 hours) is statistically significant. The opposite is true for noncoresident PHHM deaths: the death of older primeage adults is associated with a smaller decrease, a magnitude of 8 farm hours. Note that both these coefficient estimates are larger than the mean (negative) change in farm hours, indicating that adult deaths of these kinds can switch the sign of the change in farm hours at the mean. These results are consistent with the hypothesis that coresident younger adults are providing more in-kind support to their elderly relatives through farm labor, while noncoresident older adults are providing monetary support from outside the residence. Older adults adjust to each of these deaths with an increase in work burden.

In table 5, column 2, we break the PHHM death variables by whether the deceased adult was the elderly respondent's own child. The coefficients reported in column 2 show a similar trend to the results in column 1 (and the same hypothesis above would be consistent), although the PHHM not living with the older adult is not statistically significant.

In column 3, we decompose the death variables by gender of the deceased adult. We find no statistically significant evidence that female deaths, for coresident or noncoresident PHHM adults, are associated with different changes in farm labor hours for elderly respondents than male deaths. However, the size of the increase in work (although statistically not significant) for female coresident deaths is similar to that of the male nonresident deaths (about 3 more hours per week). Again, this result suggests that the contribution of these prime-age persons to the economy of the household is in-kind (labor-sharing) in the case of coresident females and is in the form of other support for nonresident males. 
In the last column in table 5, we break down the PHHM death variables by spousal status. Since there are no instances of spouses who died at ages 15-50 who were not living with the elderly individual at the time of death, this category is omitted from the regression. We find evidence that nonspouses' deaths are associated with smaller decreases in labor hours than spouses' regardless of living arrangement. In the case of coresident deaths, this finding might be explained by the fact that coresident own children and young adult deaths are associated with larger responses, and these categories of adults are mostly not spouses of the elderly respondent. In the case of noncoresident deaths, we cannot compare the extent of the association for spouses versus nonspouses because, as mentioned above, the variable for spouses is dropped in the regression.

The results in tables 4 and 5 for PHHM deaths hold if the deaths of children living outside are excluded. Together, the results of table 5 suggest that support to the elderly from coresident adults may be in the form of farm labor and young adults and children of the elderly respondents may provide this support more intensively. However, noncoresident support may be more intensively provided by older adults, whose deaths cause a greater increase in labor hours for elderly than noncoresident young adults.

\section{B. Impact of Adult Death on Labor Hours over Time}

Since the survey data also include the year of death for previous household members who died, we can look at the dynamics of the impact of experiencing a prime-age death in the household over time. We divide the time span of the panel into three periods of roughly equal length: 1991-95, 1996-99, and 2000-2004. We construct six dummy death variables, three corresponding to the deaths over time of coresident PHHM adults and three corresponding to the deaths over time of noncoresident adults. These are not mutually exclusive categories because the older adult may have had multiple death shocks across periods and for coresident as well as noncoresident adult relatives. We also include the death of a child living elsewhere. Since we do not know the time of these noncoresident children's deaths (denoted in the model below as CLE, or child living elsewhere), we cannot create the same time-specific indicators as described above.

We denote coresident PHHM deaths over time with "co" in the superscript, and noncoresident deaths with "non-co" in the subscript. The new model we estimate is the following:

$$
\begin{gathered}
\Delta y_{e j}=\alpha+\gamma_{1} d_{j}^{91-95, \mathrm{co}}+\gamma_{2} d_{j}^{96-99, \mathrm{co}}+\gamma_{3} d_{j}^{00-04, \mathrm{co}} \\
+\gamma_{1} d_{j}^{91-95, \text { non }-\mathrm{co}}+\gamma_{2} d_{j}^{96-99, \text { non-co }}+\gamma_{3} d_{j}^{00-04, \text { non-co }} \\
+\gamma_{4} d_{e j}^{\text {cle }}+\beta_{2} X_{e j}+\varepsilon_{e j} .
\end{gathered}
$$

This model allows us to look at the impact of deaths that occurred $0-4$ years ago, 5-8 years ago, and 9-13 years ago. We report the results in table 6. The dependent variable is the same as in tables 4 and 5: the change in farm hours from 1991 to 2004. We report results from four regressions. In these regressions, we examine the association of farm labor hours with adult deaths in the recent and more distant past. Estimating the extent of this association over time adds to our understanding of potential dynamics in the effects of adult mortality 
on the elderly. This aspect of our analysis is novel, and it is made possible by the length of our panel data set.

The results of the first regression suggest a pattern over time in the association between farm labor hours and adult death. For coresident prime-age adult deaths, this association is increasing (and measured more precisely as well) for deaths farther in the past. There is no significant association between noncoresident adult deaths and labor supply changes over time, but the standard errors are large for all three categories.

In the second regression, for which results are presented in the second set of rows in table 6 , we interacted the PHHM death variables with a dummy that equals one if the elderly respondent is female. We find again that the association between coresident deaths occurring in the more distant past, which we found in the first regression's results, is strongest for elderly women. However, there is an increase in farm hours for elderly men with noncoresident adult deaths, although the coefficient is not statistically significant. For these deaths occurring in the more distant past, older women's farm hours decline, although we do not have a plausible explanation for this change.

As in table 5, the gender of the deceased matters with respect to changes in farm hours (regression 3 in table 6). We find that there are small and statistically insignificant impacts of a coresident male adult death in the household but that the impact of coresident female deaths is large and statistically associated with more distant death shocks. In the final regression reported in table 6, we investigate how the effects of adult deaths over time vary by whether the deceased adult was the elderly respondent's own child. Coresident deaths of own children are associated with increases in labor hours for deaths in the middle and more distant past categories, whereas coresident deaths of adults who were not the children of the elderly are associated with an increase in labor but only for the most distant past category (9-13 years past). For the noncoresident PHHMs, a pattern is difficult to discern with the largely imprecise estimates.

In table 7, we report results for types of labor other than own farm hours. The other types of labor we focus on are chores (collecting firewood and water), nonfarm self-employment, and wage employment. As table 7 shows, deaths are not associated with changes in hours of any of these other activities, at least not with statistical significance. Some specific categories do show large magnitude in coefficients but with large standard errors (such as older adults' wage employee hours given the death of a noncoresident PHHM between 1991 and 1995). In general, however, we conclude that older adults do not appear to be responding on labor margins other than farm labor, which accounts for more than $70 \%$ of total hours worked on average.

\section{Asset Buffering and the Response of Labor Hours}

Although we find that older adults work more after experiencing a death in the household, this effect depends on the gender of the older adult and the coresidency with the deceased at the time of the death. Moreover, we see the effect mainly for deaths occurring in the more distant past. In this section, we present evidence that older adults use asset position to buffer the labor impact of adult death in their household. We interact the death indicator variables 
with baseline asset values for livestock, total physical stock, and the household's dwelling, as well as acres of land owned by the household. If assets serve to buffer the impact on farm labor supply, then we should see a negative coefficient on the interaction term: labor hours decrease less in households with fewer assets. Our asset measures are reported at the household level. The survey did not ask about which individuals held ownership over the asset.

In table 8 , we find that only livestock significantly buffers the labor response, and this impact is mainly for deaths of coresident adults. To interpret the coefficients from column 1 of table 8 , we note that ordered in terms of value of livestock at baseline, the 25th percentile of households had zero livestock value, while the 75th percentile of the same distribution owned about 8 US $\$$ of livestock. Thus, going from the 25 th to the 75 th percentile of the livestock value distribution decreases the labor supply response to coresident adult death from 4.06 to 3.04, which is a reduction of 0.96 hours, or about $24 \%$. In contrast, we find small and insignificant coefficients on the interactions with the value of physical stock and household dwelling and acres of land. We might expect that livestock value exhibits the greatest buffering behavior since livestock is a liquid asset, as compared with land holdings, owned dwellings, and other forms of assets. These results suggest that older adults, where they have livestock, can use it to compensate for having to work more in the face of a death shock.

\section{Results for Health Indicators}

The focus thus far has been on the burden of prime-age mortality on older adults with respect to having to work more hours. In this section, we extend the focus to look at various measures of well-being, mainly individual health indicators and household food consumption. Our health indicators are BMI, acute illness, chronic illness, days of restricted activity, and days of no activity. ${ }^{9}$ We report the results in table 9. Changes in BMI over the course of the panel are not significantly different for elderly individuals experiencing adult death in their households or among their nonresident biological children (col. 1). This lack of response holds for other health indicators as well, namely, chronic illness and days of restricted and no activity (cols. 4-6). These results are consistent with prior work with the short-run panel from the same data set. Ainsworth and Dayton (2003) find-using the first 4 years of the same panel—-that elderly individuals' BMI returns to its original level within 1 year of an adult death.

By contrast, column 2 of table 9 shows that the change in per capita consumption is actually significantly larger (given that the mean change in log consumption for older adults in our sample is positive) for individuals experiencing a coresident death in the near past (0-4 years ago). Since consumption is measured in baseline (1991), which is several years earlier and in most cases prior to illness onset, it is unlikely that this result captures a recovery to consumption levels before illness onset. It is consistent with low farm productivity in a setting with high population density and small landholdings in which some individuals in the household may consume more than they contribute (in this case with respect to farm output).

\footnotetext{
${ }^{9} \mathrm{We}$ also examine survival, as discussed earlier in the context of sample attrition. We find no association between mortality risks for the sample of older adults and deaths of previous household members.
} 
Thus, the loss of a household member with relatively low productivity can result in higher per capita consumption for surviving members. This effect is not observed for more distant deaths, possibly because household composition shifts over time to "redistribute" this higher consumption (though we do not provide evidence that this indeed is the case). Another explanation for this association could be that transfers-via bequests or from members of the older individual's network - after the death of the prime-age coresident spurred an increase in consumption beyond what it would otherwise have risen to from 1991 to 2004. But results on net pecuniary transfers from network members (available upon request) find no evidence for the primacy of this mechanism.

Column 3 of table 9 reports results for changes in acute illness status. We find that both coresident and noncoresident adult deaths are associated with larger increases in the probability of acute illness for deaths occurring in the more distant past. This finding seems to concur with the evidence discussed earlier that the labor supply response to adult death increases over time, and may manifest itself in increases in acute illnesses.

Apart from the acute illness results, we find no evidence that the deaths of noncoresident adults or children living outside the household have an impact on health or food consumption. We discuss this result further in the following section.

\section{Conclusion}

HIV/AIDS is drastically changing the demographic landscape in high-prevalence countries in Africa. Increases in prime-age mortality rates have resulted in "missing" working-age adults, which has implications on the well-being of surviving family members. This study focuses on one specific category, older adults, who may be especially vulnerable. This demographic group often cares for orphaned grandchildren, they may rely on remittances and other in-kind support from their adult children, and older women especially may have less secure rights to household assets when men die. The burden of deaths of household members and children may force older adults to work longer hours and suffer declines in well-being. Despite the potential pathways, few empirical studies explore these impacts.

We use panel data from Tanzania that spans 13 years to study the long-run impacts of prime-age mortality on older adults, paying attention to the gender dimension of mortality impacts. Although we find some impacts that are consistent with theories about how primeage mortality will affect older adults, some of our results are contrary to these theories.

We find that adult death is associated with increased farm hours but that this impact varies by the gender of the older adult and coresidency. Older women who suffer the loss of a coresident member among their baseline household are working 5 hours more each week, whereas on average farm hours declined slightly between 1991 and 2004 for older adults. For older men, we see a similar impact, although it is not statistically significant for deaths of nonresident members. Consistent with the notion that impacts may only emerge in the long run, these effects are concentrated among the more distant death shocks-recent deaths are not associated with increases in labor supply. So even in regions with sharp declines in HIV prevalence, some groups, such as older women, may be vulnerable to death shocks that occurred as much as 13 years in the past.

Econ Dev Cult Change. Author manuscript; available in PMC 2014 October 20. 
As for health, a more direct measure of well-being, we see few impacts associated with deaths of household members. Perhaps the most striking find-ings in this dimension are that adult deaths occurring in the recent past are associated with increases in per capita food consumption. The probability of acute illness decreases in the recent past, but it subsequently rises for deaths in the farther past. Together, these findings suggest that, in the short term, older individuals in households with an adult death may actually fare better (perhaps due to the low farming productivity of some household members in this setting or to the existence of network risk-sharing). However, in the longer term, farm work increases significantly, and we find some evidence for declines in health as well. Even in settings where HIV prevalence is low today, high rates in the past (in this context, the early 1990s) have a lingering impact on the situation of older individuals. Policies that help ensure complete markets for livestock and other forms of assets, provide asset accumulation, and preserve women's rights to property may help mitigate the long-run negative impact of prime-age deaths.

The death of a nonresident biological adult child is not associated with more work or poorer health among older adults. We do not have direct measures of the extent to which adult children support their parents who live in another household, either through cash or in-kind assistance. These results suggest that either this support is replaced by other family members or the support is much lower than is currently speculated. In their cross-country study of income sources, Carletto et al. (2007) find that transfers (including remittances from relatives) constitute less than $10 \%$ of total income in the set of African countries they examine. This is a much lower share than for other regions (East Asia, East/Central Europe, and Latin America). Of course, it is possible that the share of income from remittances is much higher for particular subgroups of households, and nonincome support (labor sharing) may be important too. We also note, however, that most of the older adults in the sample resided with at least one prime-age adult (table 2). This decreased slightly by 2004, but still fully three-quarters of these older adults resided with a working-age adult. We do not examine the subsample of older adults with no prime-age adult in the household since the sample is too small, but this may be the group for whom the death of an adult child does have an impact on working hours and health.

Although this study contributes to a more complete picture of the impact of prime-age mortality on older surviving adults by focusing on work burden and health, a caveat to the findings would be concerns of endogeneity. The main driver of prime-age adult mortality, HIV/AIDS, is associated with behaviors that call into question a causal interpretation of our findings. Short of experimental options to study the impact of adult mortality, ${ }^{10}$ we partially address this, exploiting the baseline characteristics as well as the time dimension, which largely precludes anticipation of deaths based on morbidities. Other dimensions may be important, including power and bargaining dynamics within the household and the mental

\footnotetext{
${ }^{10} \mathrm{An}$ alternative to measuring the consequences of death shocks would be to study the impact of an averted mortality. Drawing on a sample of HIV-infected households under ARV treatment, Goldstein, Thirumurthy, and Zivin (2008) take this approach in work on Kenya to assess the impact of ARV treatment on improved health and changes in labor outcomes. However, these results speak to the economic impact of morbidity among household members and not the impact of death, which may be quite different.
} 
health of the elderly. Although we do not study these changes in this article (partly due to data limitations), they are important topics for future research.

\section{Acknowledgments}

This research was supported by the World Bank's Gender and Development Group's Gender, Poverty, and Demography Initiative. We thank Martha Ainsworth, Peter Lanjouw, John McIntire, T. Paul Schultz, anonymous reviewers, and seminar participants at the Amsterdam Institute for International Development, Development Lunch Seminar at Yale, NEUDC, University of Michigan conference on "The Impact of HIV/AIDS on Older Persons in Africa and Asia," and the Gender, Poverty, and Demography Workshop at the World Bank for very useful comments. The views expressed here do not necessarily reflect those of the World Bank or its member countries.

\section{References}

Agyarko, Robert de Graft. Impact of AIDS on Older People in Africa: Zimbabwe Case Study. World Health Organization; Geneva: 2002.

Ainsworth, Martha; Dayton, Julia. The Impact of the AIDS Epidemic on the Health of the Elderly in Tanzania. World Development. 2003; 31(1):131-48.

Beegle, Kathleen. Labor Effects of Adult Mortality in Tanzanian Households. Economic Development and Cultural Change. 2005; 53(3):655-84.

Beegle, Kathleen; De Weerdt, Joachim. Methodological Issues in the Study of the Socioeconomic Consequences of HIV/AIDS. AIDS. 2008; 22(suppl 1):S89-S94. [PubMed: 18664960]

Beegle, Kathleen; De Weerdt, Joachim; Dercon, Stefan. Photocopy. World Bank; Washington, DC: 2006. Kagera Health and Development Survey (KHDS), 2004: Basic Information Document.

Beegle, Kathleen; De Weerdt, Joachim; Dercon, Stefan. Adult Mortality and Economic Growth in the Age of HIV/AIDS. Economic Development and Cultural Change. 2007; 56(2):299-326.

Beegle, Kathleen; Filmer, Deon; Stokes, Andrew; Tiererova, Lucia. World Bank Policy Research Working Paper no 4889. Washington, DC: 2009. Orphanhood and the Living Arrangements of Children in Sub-Saharan Africa.

Carletto, Gero; Covarrubias, Katia; Davis, Benjamin; Krausova, Marika; Sta-moulis, Kostas; Winters, Paul. Rural Income Generating Activities in Developing Countries: Re-assessing the Evidence. Journal of Agricultural and Development Economics. 2007; 4(1):146-93.

Carter, Michael; May, Julian; Aguëro, Jorge; Ravindranath, Sonya. The Economic Impact of Premature Adult Mortality: Panel Data Evidence from KwaZulu Natal, South Africa. AIDS. 2007; 21(suppl 7):S67-S73. [PubMed: 18040167]

Centers for Disease Control and Prevention. Morbidity and Mortality Weekly Report no 49. 2000. Cause-Specific Adult Mortality: Evidence from Community-Based Surveillance; Selected Sites, Tanzania, 1992-1998; p. 416-19.

Cleave, John. African Farmers: Labor Use in the Development of Smallholder Agriculture. New York: Praeger; 1974.

Cohen, Barney; Menken, Jane, editors. Aging in Sub-Saharan Africa: Recommendation for Furthering Research. Washington, DC: National Research Council of the National Academies; 2006.

Dayton, Julia; Ainsworth, Martha. The Elderly and AIDS: Coping Strategies and Health Consequences in Rural Tanzania. Social Science and Medicine. 2004; 59(10):2161-72. [PubMed: 15351481]

du Guerny, Jacques. Photocopy. Social Development Department, Food and Agricultural Organization, United Nations; New York: 2002. The Elderly, HIV/AIDS and Sustainable Rural Development.

Fenton, Lynda. Preventing HIV/AIDS through Poverty Reduction: The Only Sustainable Solution? Lancet. 2004; 364(9440):1186-87. [PubMed: 15451230]

Ferreira, Monika. HIV/AIDS and Family Well-Being in Southern Africa: Towards an Analysis of Policies and Responsiveness. UN Department of Economic and Social Affairs Division for Social Policy and Development Policy Workshop; Windhoek, Namibia. 2004.

Gillespie, Stuart; Kadiyala, Suneetha; Greener, Robert. Is Poverty or Wealth Driving HIV Transmission? AIDS. 2007; 21(7):S5-S16. [PubMed: 18040165] 
Glick, Peter. SAGA working paper, Strategies and Analysis for Growth and Access. Cornell and Clark Atlanta Universities; 2007. Reproductive Health and Behavior, HIV/AIDS, and Poverty in Africa.

Goldstein, Markus; Thirumurthy, Harsha; Zivin, Joshua Graff. The Economic Impact of AIDS Treatment: Labor Supply in Western Kenya. Journal of Human Resources. 2008; 43(3):511-52. [PubMed: 22180664]

Hosegood, Victoria; Timaeus, Ian M. Cohen and Menken. 2006. HIV/AIDS and Older People in South Africa.

Knodel, John; Van Landingham, Mark. The Impact of the AIDS Epidemic on Older Persons. AIDS. 2002; 16(suppl 4):S77-S83. [PubMed: 12699003]

Knodel, John; Watkins, Susan; Van Landingham, Mark. AIDS and Older Persons: An International Perspective. Journal of Acquired Immune Deficiency Syndromes and Human Retrovirology. 2003 Jun.33:S153-S165.

Kwesigabo, Gideon; Killewo, Japhet; Urassa, Willy; Lugalla, Joe; Emmelin, Maria; Mutembei, Aldin; Mhalu, Fred; Biberfeld, Gunnel; Wall, Stig; Sandstrom, Anita. HIV-1 Infection Prevalence and Incidence Trends in Areas of Contrasting Levels of Infection in the Kagera Region, Tanzania, 1987-2000. Journal of Acquired Immune Deficiency Syndromes. 2005; 40(5):585-91. [PubMed: 16284536]

Messkoub, Mehmood. Social Security and Population Ageing in Sub-Saharan Africa. DevIssues. 2008; 10(2):19-20.

Mishra, Vinod; Bignami, Simona; Greener, Robert; Vaessen, Martin; Hong, Rathavuth; Ghys, Peter; Boerma, Ties; Van Assche, Ari; Khan, Shane; Rutstein, Shea. HIV Infection Does Not Disproportionately Affect the Poorer in Sub-Saharan Africa. AIDS. 2007; 21(suppl 7):S17-S28. [PubMed: 18040161]

Naidu, Veni; Harris, Geoff. The Impact of HIV/AIDS Morbidity and Mortality on Households: A Review of Household Studies. South African Journal of Economics. 2005; 73(1):533-44.

Ogunmefun, Catherine. Hidden Impacts: 'Near Old' Women's Experiences of Adult Morbidity and Mortality in Rural South Africa. Paper presented at the Fifth African Population Conference; Arusha, Tanzania. December 10-14; 2007.

Philipson, Tomas; Posner, Richard A. The Microeconomics of the AIDS Epidemic in Africa. Population and Development Review. 1995; 21(4):835-48.

Republic of Malawi and the World Bank. Malawi Poverty and Vulnerability Assessment: Investing in Our Future. Washington, DC: World Bank; 2007.

Shelton, James D.; Cassell, Michael M.; Adetunji, Jacob. Is Poverty or Wealth at the Root of HIV? Lancet. 2005; 366(9491):1057-58. [PubMed: 16182881]

Steinberg, Malcolm; Johnson, Saul; Schierhout, Gill; Ndegqwa, David. Hitting Home: How Households Cope with the Impact of the HIV/AIDS Epidemic: A Survey of the Households Hit by HIV/AIDS in South Africa. Henry J. Kaiser Family Foundation; Washington, DC: 2002.

UNICEF. The State of the World's Children 2005: Childhood under Threat. 2004. http:// www.unicef.org/

Wojcicki, Janet Maia. Socioeconomic Status as a Risk Factor for HIV Infection in Women in East, Central and Southern Africa: A Systematic Review. Journal of Biosocial Science. 2005; 37(1):136. [PubMed: 15688569]

Wooldridge, Jeffrey. Econometric Analysis of Cross Section and Panel Data. Cambridge, MA: MIT Press; 2001.

World Bank. World Bank Policy Research Report. World Bank; Washington, DC: 1997. Confronting AIDS: Public Priorities in a Global Epidemic.

World Bank. User's Guide to the Kagera Health and Development Survey Da-tasets. World Bank Policy Research Report, Development Research Group, World Bank; Washington, DC: 2004. 


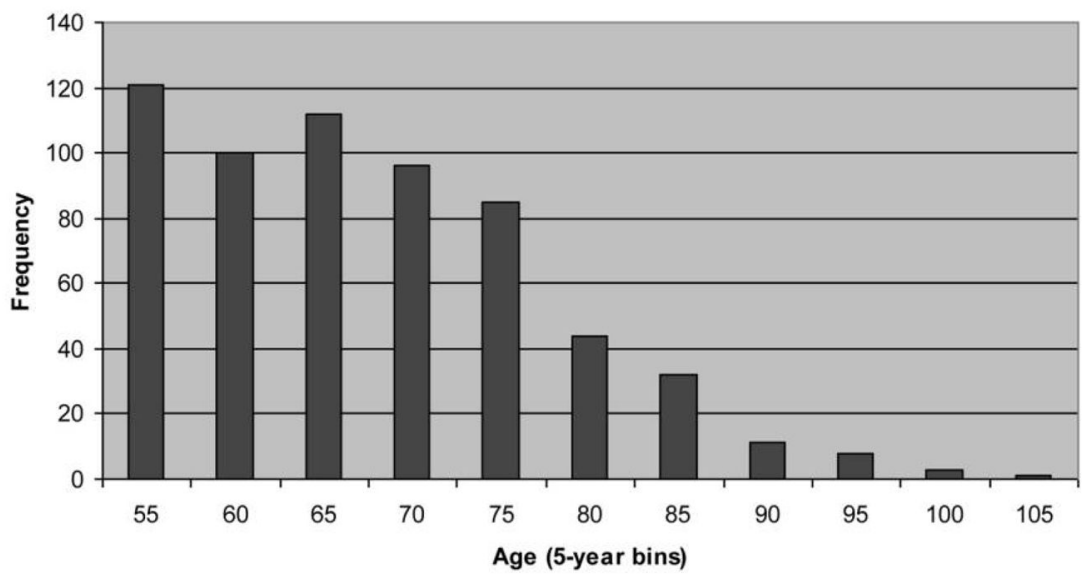

Figure 1.

Histogram of age of older adult sample 


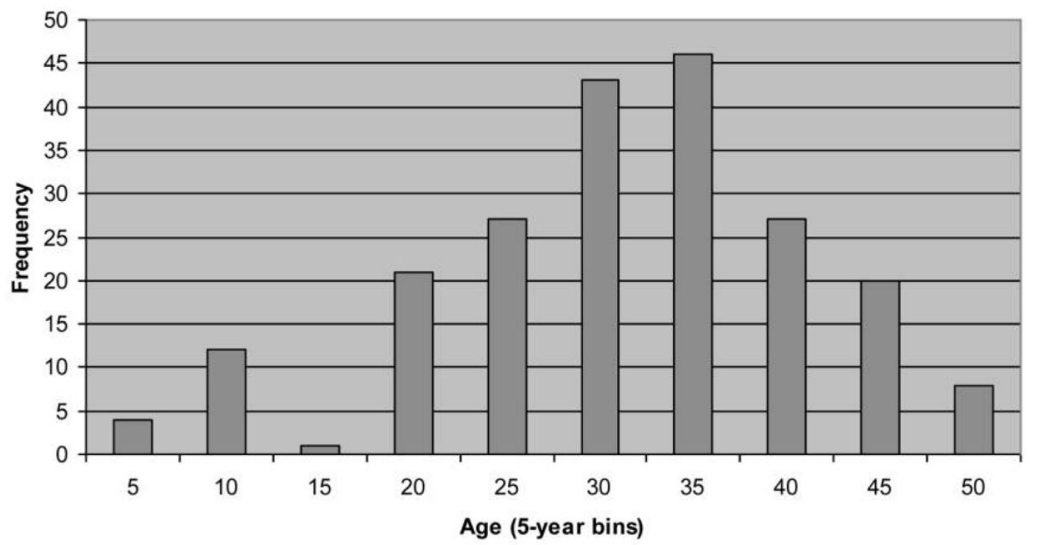

Figure 2.

Histogram of age at death of adult household members 


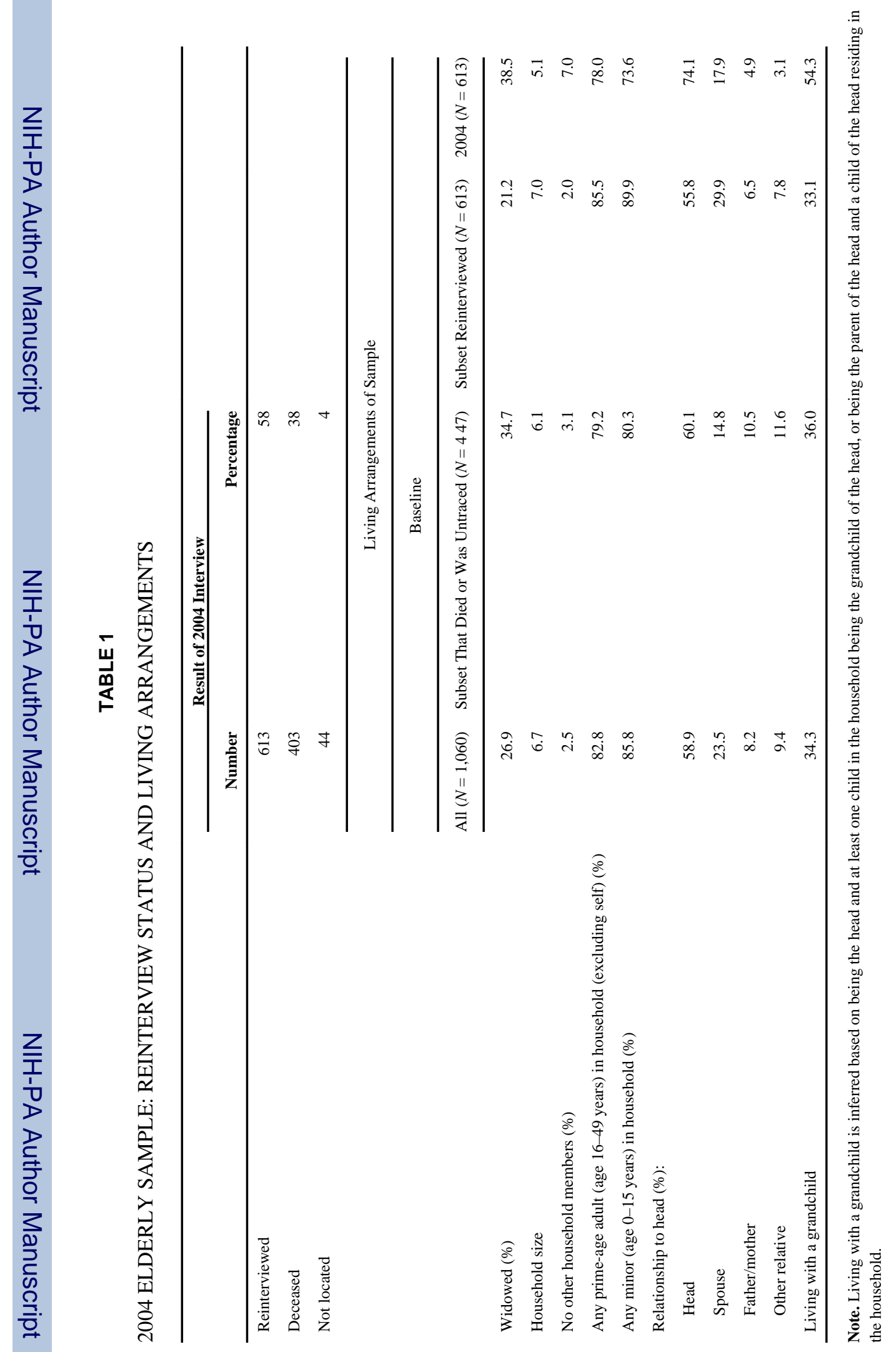


TABLE 2

SUMMARY STATISTICS FOR 2004 SAMPLE OF OLDER INDIVIDUALS (MEANS)

\begin{tabular}{|c|c|c|c|c|}
\hline & \multirow[b]{2}{*}{ All (1) } & \multicolumn{3}{|c|}{ Reinterviewed in 2004} \\
\hline & & All (2) & No Death (3) & Any Death (4) \\
\hline Female $(\%)$ & .54 & $.59^{*}$ & .55 & $.64^{*}$ \\
\hline Education (highest grade completed) & $2.75(2.91)$ & $2.84(2.87)$ & $2.84(2.85)$ & $2.83(2.92)$ \\
\hline Age at baseline & $56.34(13.12)$ & $52.49^{*}(10.14)$ & $52.08(10.42)$ & $53.25(9.91)$ \\
\hline \multicolumn{5}{|l|}{ Baseline: } \\
\hline Farm hours & $14.74(13.28)$ & $16.66^{*}(13.50)$ & $17.56(13.58)$ & $14.92^{*}(13.21)$ \\
\hline Hours collecting firewood and water & $2.12(4.14)$ & $2.28(4.19)$ & $2.50(4.48)$ & $1.85^{*}(3.53)$ \\
\hline Wage employment hours & $4.10(12.91)$ & $3.95(12.62)$ & $3.27(10.90)$ & $5.25^{*}(15.34)$ \\
\hline Self-employment, nonfarm hours & $1.86(8.56)$ & $1.65(7.63)$ & $1.30(6.34)$ & $2.33(9.61)$ \\
\hline Body mass index & $20.48(3.09)$ & $20.77^{*}(3.08)$ & $20.69(3.12)$ & $20.92(2.99)$ \\
\hline Acute illness (\%) & .56 & $.51^{*}$ & .51 & .52 \\
\hline Chronic illness (\%) & .43 & $.38^{*}$ & .38 & .38 \\
\hline \multicolumn{5}{|l|}{ 2004: } \\
\hline Farm hours & & $15.32(14.40)$ & $15.29(14.47)$ & $15.39(14.44)$ \\
\hline Hours collecting firewood and water & & $1.46(3.27)$ & $1.47(3.06)$ & $1.43(3.65)$ \\
\hline Wage employment hours & & $2.72(12.07)$ & $2.66(12.08)$ & $2.82(12.09)$ \\
\hline Self-employment, nonfarm hours & & $1.99(9.51)$ & $1.55(7.69)$ & $2.82(12.22)$ \\
\hline Body mass index & & $20.36(3.07)$ & $20.04(3.00)$ & $20.96^{*}(3.13)$ \\
\hline Acute illness (\%) & & .65 & .65 & .65 \\
\hline Chronic illness (\%) & & .53 & .51 & .56 \\
\hline \multicolumn{5}{|l|}{ Coresident PHHM who died from ages 15-50: } \\
\hline 1991-95 & & .09 & & \\
\hline $1996-99$ & & .07 & & \\
\hline $2000-2004$ & & .10 & & \\
\hline \multicolumn{5}{|l|}{ Noncoresident PHHM who died from ages $15-50$ : } \\
\hline $1991-95$ & & .02 & & \\
\hline 1996-99 & & .04 & & \\
\hline $2000-2004$ & & .05 & & \\
\hline Child living outside household aged 15-50 (in 1991) who died & & .13 & & \\
\hline No. observations & 1,060 & 613 & 402 & 211 \\
\hline
\end{tabular}

Note. Hours refer to hours in the past 7 days. PHHM is a "previous household member" residing with the older adult at the time of death. Standard errors are in parentheses.

*

Statistically significant differences between cols. 1 and 2 and between cols. 3 and 4 are at the $5 \%$ level. 


\section{TABLE 3}

\section{BASELINE CORRELATES OF ATTRITION}

\begin{tabular}{|c|c|c|c|c|}
\hline & All (1) & Women (2) & Men (3) & All (4) \\
\hline Female & $.214^{* *}(.105)$ & & & $.215^{* *}(.106)$ \\
\hline $\begin{array}{l}\text { Living with PHHM who died from ages 15-50 between } 1991 \\
\text { and } 1994\end{array}$ & & & & $-.014(.246)$ \\
\hline Education (highest grade completed) & $-.017(.019)$ & $-.008(.029)$ & $-.016(.026)$ & $-.017(.019)$ \\
\hline Age (/10) & $1.261^{* * *}(.334)$ & $1.407^{* * *}(.462)$ & $1.352^{* *}(.552)$ & $1.261^{* * *}(.334)$ \\
\hline$(\text { Age })^{2}(/ 100)$ & $-.136^{* * *}(.029)$ & $-.146^{* * *}(.040)$ & $-.150^{* * *}(.048)$ & $-.136^{* * *}(.029)$ \\
\hline Baseline widow status & $-.148(.112)$ & $-.067(.130)$ & $-.320(.230)$ & $-.148(.112)$ \\
\hline \multicolumn{5}{|l|}{ Health: } \\
\hline Body mass index & $.015^{* *}(.007)$ & $.018^{* *}(.009)$ & $.010(.011)$ & $.015^{* *}(.007)$ \\
\hline Illness $>6$ months & $-.117(.091)$ & $.005(.126)$ & $-.338^{* *}(.139)$ & $-.117(.091)$ \\
\hline Ill in the past 4 weeks & $-.092(.097)$ & $-.136(.135)$ & $.055(.142)$ & $-.092(.097)$ \\
\hline Days of no activity & $-.046(.038)$ & $-.110^{* *}(.054)$ & $.030(.062)$ & $-.046(.039)$ \\
\hline Days of restricted activity & $-.010(.033)$ & $.059(.049)$ & $-.084^{*}(.051)$ & $-.011(.033)$ \\
\hline \multicolumn{5}{|l|}{ Labor supply, hours last week: } \\
\hline Farm & $.004(.004)$ & $.000(.005)$ & $.009(.006)$ & $.004(.004)$ \\
\hline Collecting firewood and water & $-.008(.010)$ & $.006(.013)$ & $-.034 *(.019)$ & $-.008(.010)$ \\
\hline Wage employment & $-.004(.003)$ & $.005(.011)$ & $-.007^{*}(.004)$ & $-.004(.003)$ \\
\hline Self-employment, nonfarm & $-.009^{*}(.005)$ & $-.017^{* *}(.008)$ & $-.006(.008)$ & $-.009^{*}(.005)$ \\
\hline \multicolumn{5}{|l|}{ Value of assets at baseline: } \\
\hline Business & $-.213(.139)$ & $-.319(.260)$ & $-.114(.116)$ & $-.213(.139)$ \\
\hline Durable goods & $.008(.011)$ & $.043(.027)$ & $-.017(.023)$ & $.008(.011)$ \\
\hline Farm equipment & $.230(.205)$ & $.054(.401)$ & $.265(.188)$ & $.231(.205)$ \\
\hline Farm buildings & $.506(.428)$ & $-.921(.924)$ & $1.760(1.091)$ & $.506(.428)$ \\
\hline Livestock & $-.060(.043)$ & $-.106^{*}(.059)$ & $.098(.114)$ & $-.060(.043)$ \\
\hline Owned dwellings & $.002(.017)$ & $.017(.025)$ & $-.006(.025)$ & $.002(.017)$ \\
\hline Unowned dwellings & $-.023(.015)$ & $-.022^{* *}(.010)$ & $-.040(.062)$ & $-.023(.015)$ \\
\hline Land & $.019^{*}(.010)$ & $.036^{* *}(.015)$ & $-.003(.013)$ & $.019^{*}(.010)$ \\
\hline No. observations & 1,049 & 575 & 474 & 1,049 \\
\hline
\end{tabular}

Note. Dependent variable is indicator for alive in 2004. Results of a probit model are reported. Includes controls for sample enumeration area classification. Excludes 11 observations missing information on assets. PHHM is a "previous household member" residing with the older adult at the time of death. Robust standard errors are in parentheses.

* Significant at the $10 \%$ level.

** Significant at the $5 \%$ level.

Significant at the $1 \%$ level.

Econ Dev Cult Change. Author manuscript; available in PMC 2014 October 20. 
TABLE 4

\section{IMPACT OF ADULT DEATH ON OWN FARM LABOR HOURS IN PAST 7 DAYS}

\begin{tabular}{|c|c|c|c|}
\hline & (1) & (2) & (3) \\
\hline PHHM who died ages $15-50$ or child living outside household died ages $15-50$ & $1.665(1.739)$ & & \\
\hline Coresident PHHM who died ages $15-50$ & & $2.489(1.822)$ & $-.968(2.736)$ \\
\hline Interacted with female indicator & & & $5.610 *(3.381)$ \\
\hline Noncoresident PHHM who died ages $15-50$ & & $3.530(2.914)$ & $6.182^{*}(3.690)$ \\
\hline Interacted with female indicator & & & $-4.392(5.097)$ \\
\hline Child living outside household age 15-50 (in 1991) who died & & $-1.108(2.449)$ & $-1.549(2.478)$ \\
\hline Mean change in farm hours & & -1.5 & \\
\hline
\end{tabular}

Note. Dependent variable is farm hours last week 2004 minus farm hours last week 1991. Number of observations =561. PHHM is a "previous household member." Observations are weighted using inverse probability weights (based on table 3, discussed in the text). Includes controls from baseline for gender, age and age squared, education, number of children ages 15-50 living outside the household, season of interview, asset values, household size, and sample enumeration area classification. Also included are illness and crop shock variables between baseline and 2004. Robust standard errors are in parentheses.

* Significant at the $10 \%$ level. 
TABLE 5

\section{IMPACT OF ADULT DEATH ON OWN FARM LABOR HOURS IN PAST 7 DAYS, BY CHARACTERISTICS OF DECEASED ADULTS}

\begin{tabular}{|c|c|c|c|c|}
\hline Characteristic of Deceased Adult & $\begin{array}{l}\text { Young Adult (Ages } \\
\text { 15-29) (1) }\end{array}$ & $\begin{array}{l}\text { Child of Elderly } \\
\text { Individual (2) }\end{array}$ & Female Adult (3) & $\begin{array}{l}\text { Spouse of Elderly } \\
\text { Individual (4) }\end{array}$ \\
\hline $\begin{array}{l}\text { Coresident PHHM who died age } 15-50 \text {, having } \\
\text { specified characteristic }\end{array}$ & $5.316^{* *}(2.310)$ & $3.460(2.390)$ & $2.957(2.299)$ & $-1.113(3.943)$ \\
\hline $\begin{array}{l}\text { Coresident PHHM who died age } 15-50 \text {, not } \\
\text { having specified characteristic }\end{array}$ & $.845(2.142)$ & $1.234(2.226)$ & $1.513(2.483)$ & $3.591(2.579)$ \\
\hline $\begin{array}{l}\text { Noncoresident PHHM who died age 15-50, } \\
\text { having specified characteristic }\end{array}$ & $-3.259(3.305)$ & $1.069(3.893)$ & $1.211(3.029)$ & NA \\
\hline $\begin{array}{l}\text { Noncoresident PHHM who died age } 15-50 \text {, not } \\
\text { having specified characteristic }\end{array}$ & $8.792^{* *}(3.437)$ & $4.240(3.485)$ & $4.679(4.799)$ & $5.195(3.597)$ \\
\hline $\begin{array}{l}\text { Child living outside household age } 15-50 \text { (in } \\
\text { 1991) who died }\end{array}$ & $-1.754(2.392)$ & $-1.228(2.461)$ & $-1.271(2.482)$ & $-1.056(3.580)$ \\
\hline No. observations & 561 & 561 & 561 & 271 \\
\hline
\end{tabular}

Note. Dependent variable is farm hours last week 2004 minus farm hours last week 1991. Observations are weighted using inverse probability weights (based on table 3, discussed in the text). Includes controls from baseline for gender, age and age squared, education, number of children ages 15-50 living outside the household, season of interview, asset values, household size, and sample enumeration area classi-fication. Also included are illness and crop shock variables between baseline and 2004. PHHM is a "previous household member." There are no instances of a PHHM who died at age 15-50 while not living with the elderly respondent who were the spouse of the elderly individual; thus, this variable is dropped in col. 4. Robust standard errors are in parentheses.

**

Significant at the $5 \%$ level. 
TABLE 6

THE IMPACT OF ADULT DEATH ON HOURS SPENT ON OWN FARM BY NUMBER OF YEARS SINCE DEATH

\begin{tabular}{lccc}
\hline & \multicolumn{2}{c}{ Year in Which Death Occurred } \\
\cline { 2 - 4 } & \multicolumn{1}{c}{$\mathbf{1 9 9 1 - 9 5}$} & $\mathbf{1 9 9 6 - 9 9}$ & 2000-2004 \\
\hline Regression 1: & & & \\
$\quad$ Coresident PHHM who died from age 15-50 & $5.716^{*}(3.094)$ & $2.462(2.501)$ & $-1.251(2.419)$ \\
Noncoresident PHHM who died from age 15-50 & $-6.078(4.571)$ & $4.976(4.502)$ & $4.127(3.338)$ \\
Regression 2: & & & \\
Coresident PHHM who died from age 15-50 & $-1.892(4.890)$ & $3.144(4.030)$ & $-1.157(3.846)$ \\
$\quad$ Interaction with female indicator & $12.623^{* *}(5.189)$ & $-.910(5.029)$ & $.232(4.111)$ \\
$\quad$ Noncoresident PHHM who died from age 15-50 & $3.499(4.015)$ & $7.715(7.157)$ & $5.964(4.712)$ \\
$\quad$ Interaction with female indicator & $-12.889^{* *}(5.267)$ & $-4.249(8.326)$ & $-4.857(6.250)$ \\
Regression 3: & & & \\
Coresident female PHHM who died from age 15-50 & $11.691^{* * *}(3.351)$ & $.943(3.489)$ & $-3.281(2.735)$ \\
Coresident male PHHM who died from age 15-50 & $-.232(4.072)$ & $2.503(3.362)$ & $2.586(3.893)$ \\
Noncoresident female PHHM who died from age 15-50 & $-6.462(4.460)$ & $5.357(5.535)$ & $2.763(3.657)$ \\
Noncoresident male PHHM who died from age 15-50 & $-5.869(12.598)$ & $4.626(7.348)$ & $2.428(4.043)$ \\
Regression 4: & & & \\
Coresident own child PHHM who died from age 15-50 & $3.400(3.814)$ & $5.049^{*}(2.978)$ & $-1.472(3.818)$ \\
Coresident non-own child PHHM who died from age 15-50 & $9.344^{* * *(3.445)}$ & $-1.270(3.485)$ & $-1.614(3.029)$ \\
Noncoresident own child PHHM who died from age 15-50 & $-13.021(7.994)$ & $3.320(6.949)$ & $4.905(4.532)$ \\
Noncoresident non-own child PHHM who died age 15-50 & $-1.158(4.779)$ & $5.996(5.708)$ & $5.584(4.568)$ \\
\hline
\end{tabular}

Note. Dependent variable in all columns is farm hours last week 2004 minus farm hours last week 1991. The table presents results from four separate regressions. Observations are weighted using inverse probability weights (based on table 3, discussed in the text). Includes controls from baseline for gender, age and age squared, education, number of children ages 15-50 living outside the household, season of interview, asset values, household size, and sample enumeration area classification. Also included are illness and crop shock variables between baseline and 2004 . The number of observations in each regression is 561. PHHM is a "previous household member." Robust standard errors are in parentheses.

* Significant at the $10 \%$ level.

*** Significant at the $5 \%$ level.

*** Significant at the $1 \%$ level. 
TABLE 7

THE IMPACT OF ADULT DEATH ON LABOR HOURS

\begin{tabular}{lcccc}
\hline & \multicolumn{4}{c}{ Dependent Variable } \\
\cline { 2 - 5 } & $\begin{array}{c}\text { Change in Total Hours } \\
\mathbf{( 1 )}\end{array}$ & $\begin{array}{c}\text { Change in Chore } \\
\text { Hours (2) }\end{array}$ & $\begin{array}{c}\text { Change in Self- } \\
\text { Employment (3) }\end{array}$ & $\begin{array}{c}\text { Change in } \\
\text { Employment Hours (4) }\end{array}$ \\
\hline Coresident PHHM who died age 15-50: & & & & \\
1 1991-95 & $3.186(3.444)$ & $.808(.545)$ & $.374(1.015)$ & $-.781(1.321)$ \\
$1996-99$ & $1.916(3.915)$ & $1.010(.642)$ & $-.519(.925)$ & $-2.599(1.800)$ \\
2000-2004 & $-.307(3.002)$ & $-.195(.470)$ & $.028(.928)$ & $.745(.692)$ \\
Noncoresident PHHM who died & & & & $-6.289(4.148)$ \\
age 15-50: & $-9.626(9.444)$ & $-.888(1.246)$ & $-.415(.832)$ & $.039(1.218)$ \\
1991-95 & $4.677(5.494)$ & $-.634(.991)$ & $.081(1.798)$ & $-.519(1.291)$ \\
1996-99 & $5.673(4.361)$ & $.216(.548)$ & $-.258(.394)$ & $-.776(.893)$ \\
2000-2004 & $-.104(2.981)$ & $.262(.622)$ & $.160(.625)$ & -1.1 \\
Child living outside household \\
age 15-50 (in 1991) who died
\end{tabular}

Note. Observations are weighted using inverse probability weights (based on table 3, discussed in the text). Includes controls from baseline for gender, age and age squared, education, number of children ages 15-50 living outside the household, season of interview, asset values, household size, and sample enumeration area classification. Also included are illness and crop shock variables between baseline and 2004. PHHM is a "previous household member." Robust standard errors are in parentheses. 
TABLE 8

\section{ASSET BUFFERING AND THE IMPACT OF ADULT DEATH ON FARM HOURS}

\begin{tabular}{|c|c|c|c|c|}
\hline & (1) & (2) & (3) & (4) \\
\hline Living with PHHM who died from age $15-50$ & $3.894^{* *}(1.931)$ & $4.788^{*}(2.486)$ & $2.389(2.113)$ & $2.120(2.643)$ \\
\hline Not living with PHHM who died from age $15-50$ & $3.944(2.831)$ & $3.247(3.235)$ & $3.124(3.032)$ & $5.227(3.986)$ \\
\hline \multicolumn{5}{|l|}{ Coresident PHHM who died from age $15-50$ interacted with: } \\
\hline Value of livestock at baseline & $-13.405^{* * *}(4.377)$ & & & \\
\hline Value of physical stock at baseline & & $-.696(.616)$ & & \\
\hline Value of owned dwelling at baseline & & & $.118(1.480)$ & \\
\hline Acres of land owned at baseline & & & & $.049(.374)$ \\
\hline \multicolumn{5}{|l|}{ Noncoresident PHHM who died from age $15-50$ interacted with: } \\
\hline Value of livestock at baseline & $-7.855(5.272)$ & & & \\
\hline Value of physical stock at baseline & & $-.105(.421)$ & & \\
\hline Value of owned dwelling at baseline & & & $621(1.179)$ & \\
\hline Acres of land owned at baseline & & & & $-.339(.437)$ \\
\hline Child living outside household age 15-50 (in 1991) who died & $-2.073(2.586)$ & $-1.775(2.644)$ & $-1.058(2.496)$ & $-.334(3.068)$ \\
\hline No. observations & 561 & 550 & 561 & 561 \\
\hline
\end{tabular}

Note. Dependent variable is farm hours last week 2004 minus farm hours last week 1991. Observations are weighted using inverse probability weights (based on table 3, discussed in the text). Includes controls from baseline for gender, age and age squared, education, number of children ages 15-50 living outside the household, season of interview, asset values, household size, and sample enumeration area classi-fication. Also included are illness and crop shock variables between baseline and 2004. PHHM is "previous household member." Interactions of asset variables with child living outside the household are included in regressions, but their coefficients are not reported. Robust standard errors are in parentheses.

Significant at the $10 \%$ level.

Significant at the $5 \%$ level.

Significant at the $1 \%$ level. 


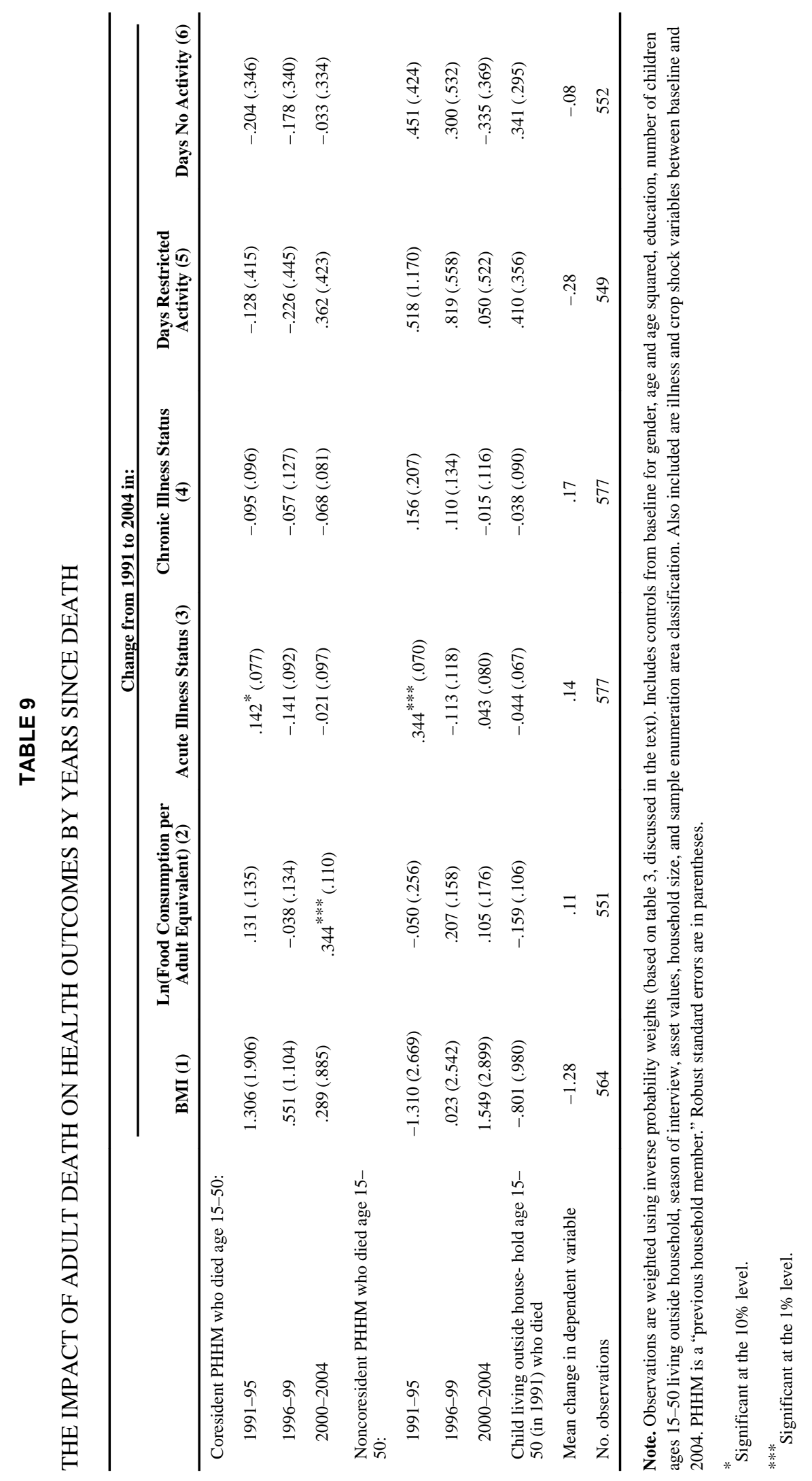

Econ Dev Cult Change. Author manuscript; available in PMC 2014 October 20. 